\title{
Efficient display of active lipase LipB52 with a Pichia pastoris cell surface display system and comparison with the LipB52 displayed on Saccharomyces cerevisiae cell surface Zhengbing Jiang ${ }^{\dagger 1}{ }^{2}$, Bei Gao ${ }^{\dagger 1}$, Ren Ren ${ }^{\dagger 1}$, Xingyi Tao ${ }^{1}$, Yushu $\mathrm{Ma}^{1}$ and Dongzhi Wei*1
}

Address: ${ }^{1}$ State Key Laboratory of Bioreactor Engineering, Newworld Institute of Biotechnology, East China University of Science and Technology, Shanghai 200237, P. R. China and ${ }^{2}$ College of Life Science, Hubei University, Wuhan 430062, P. R. China

Email: Zhengbing Jiang - zhbjiang@hubu.edu.cn; Bei Gao - bingmengl@163.com; Ren Ren - renren_800725@yahoo.com.cn; XingyiTao - taoxy066@126.com; Yushu Ma - myushu@ecustedu.cn; Dongzhi Wei* - dzhwei@ecust.edu.cn

* Corresponding author †Equal contributors

Published: 28 january 2008

BMC Biotechnology 2008, 8:4 doi:10.1 186/1472-6750-8-4

This article is available from: http://www.biomedcentral.com/1472-6750/8/4

(C) 2008 Jiang et al; licensee BioMed Central Ltd.

This is an Open Access article distributed under the terms of the Creative Commons Attribution License (http://creativecommons.org/licenses/by/2.0), which permits unrestricted use, distribution, and reproduction in any medium, provided the original work is properly cited.

\begin{abstract}
Background: For industrial bioconversion processes, the utilization of surface-displayed lipase in the form of whole-cell biocatalysts is more advantageous, because the enzymes are displayed on the cell surface spontaneously, regarded as immobilized enzymes.

Results: Two Pichia pastoris cell surface display vectors based on the flocculation functional domain of FLO with its own secretion signal sequence or the $\alpha$-factor secretion signal sequence were constructed respectively. The lipase gene lipB52 fused with the FLO gene was successfully transformed into Pichia pastoris KM7I. The lipase LipB52 was expressed under the control of the AOXI promoter and displayed on Pichia pastoris KM7I cell surface with the two Pichia pastoris cell surface display vectors. Localization of the displayed LipB52 on the cell surface was confirmed by the confocal laser scanning microscopy (CLSM). The LipB52 displayed on the Pichia pastoris cell surface exhibited activity toward $p$-nitrophenol ester with carbon chain length ranging from $C_{10}$ to $\mathrm{C}_{18}$, and the optimum substrate was $p$-nitrophenol-caprate $\left(\mathrm{C}_{10}\right)$, which was consistent with it displayed on the Saccharomyces cerevisiae EBYI00 cell surface. The hydrolysis activity of lipase LipB52 displayed on Pichia pastoris KM7I-pLHJ047 and KM7I-pLHJ048 cell surface reached 94 and 91 U/g dry cell, respectively. The optimum temperature of the displayed lipases was $40^{\circ} \mathrm{C}$ at $\mathrm{pH} 8.0$, they retained over $90 \%$ activity after incubation at $60^{\circ} \mathrm{C}$ for 2 hours at $\mathrm{pH} 7.0$, and still retained $85 \%$ activity after incubation for 3 hours.
\end{abstract}

Conclusion: The LipB52 displayed on the Pichia pastoris cell surface exhibited better stability than the lipase LipB52 displayed on Saccharomyces cerevisiae cell surface. The displayed lipases exhibited similar transesterification activity. But the Pichia pastoris dry cell weight per liter (DCW/L) ferment culture was about 5 times than Saccharomyces cerevisiae, the lipase displayed on Pichia pastoris are more suitable for whole-cell biocatalysts than that displayed on Saccharomyces cerevisiae cell surface. 


\section{Background}

Lipases (E.C.3.1.1.3) are esterases able to hydrolyze waterinsoluble esters, which have a wide range of potential industrial applications [1-3]. Pseudomonas lipases display special biochemical characteristics differing from those produced by other microorganisms $[1,4-6]$. The lipase LipB52 encoded by lipB52 (GenBank accession number AY623009), isolated from Pseudomonas fluorescens B52, displayed high level enantioselectivity with $(R)$-tert-leucinate [7]. For industrial bioconversion processes, the utilization of surface-displayed lipase in the form of wholecell biocatalysts is more advantageous, because the enzymes are displayed on the cell surface spontaneously, regarded as immobilized enzyme, and can be separated easily. With the recent development of cell-surface display technology, many active enzymes can be genetically immobilized on Saccharomyces cerevisiae cell surface $[8,9]$, while displaying active enzymes on Pichia pastoris cell surface was rarely reported $[10,11]$. In fact, the $P$. pastoris expression system has gained acceptance as an important host organism[12], and is common for high level expression of foreign proteins.

In this paper, we have the lipase LipB52 displayed on Pichia pastoris KM71 cell surface with a Pichia pastoris cell surface display system based on the FLO gene encoding a lectin-like cell-wall protein (FLO) from Saccharomyces cerevisiae [13]. FLO is composed of several domains: the secretion signal domain, the flocculation functional domain, the glycosyl phosphatidylinositol (GPI) anchor attachment signal domain and the membraneanchoring domain [14-16]. The FLO flocculation functional domain, thought to be located near the N-terminus, recognizes and adheres noncovalently to cell-wall components such as $\alpha$-mannan carbohydrates, causing reversible aggregation of cells into flocs $[13,14,16]$. The 5'-terminus of lipase gene lipB52 was fused to the 3'-terminus of the FLO gene with the secretion signal sequence of FLO or the $\alpha$-factor secretion signal sequence, and the fused gene was transformed into a heterologous fungal host, Pichia pastoris KM71. The lipase LipB52 was expressed under the control of the AOX1 promoter and displayed on Pichia pastoris KM71 cell surface. Localization of the expressed lipase LipB52 on the cell surface was confirmed by the confocal laser scanning microscopy (CLSM). Some biochemical characteristics of the lipase LipB52 displayed on Pichia pastoris KM71 cell surface were also analysed and compared with the LipB52 displayed on Saccharomyces cerevisiae EBY100-pLHJ026 cell surface.

\section{Results}

Construction of the recombinant plasmids of FLO-lipB52 and expression of fusion proteins

The recombinant plasmids pLHJ047 and pLHJ048 (Fig. 1) were constructed as described in Methods. The FLO sequence was cloned in the frame and downstream of the $\alpha$-factor secretion signal sequence in pLHJ048, while the
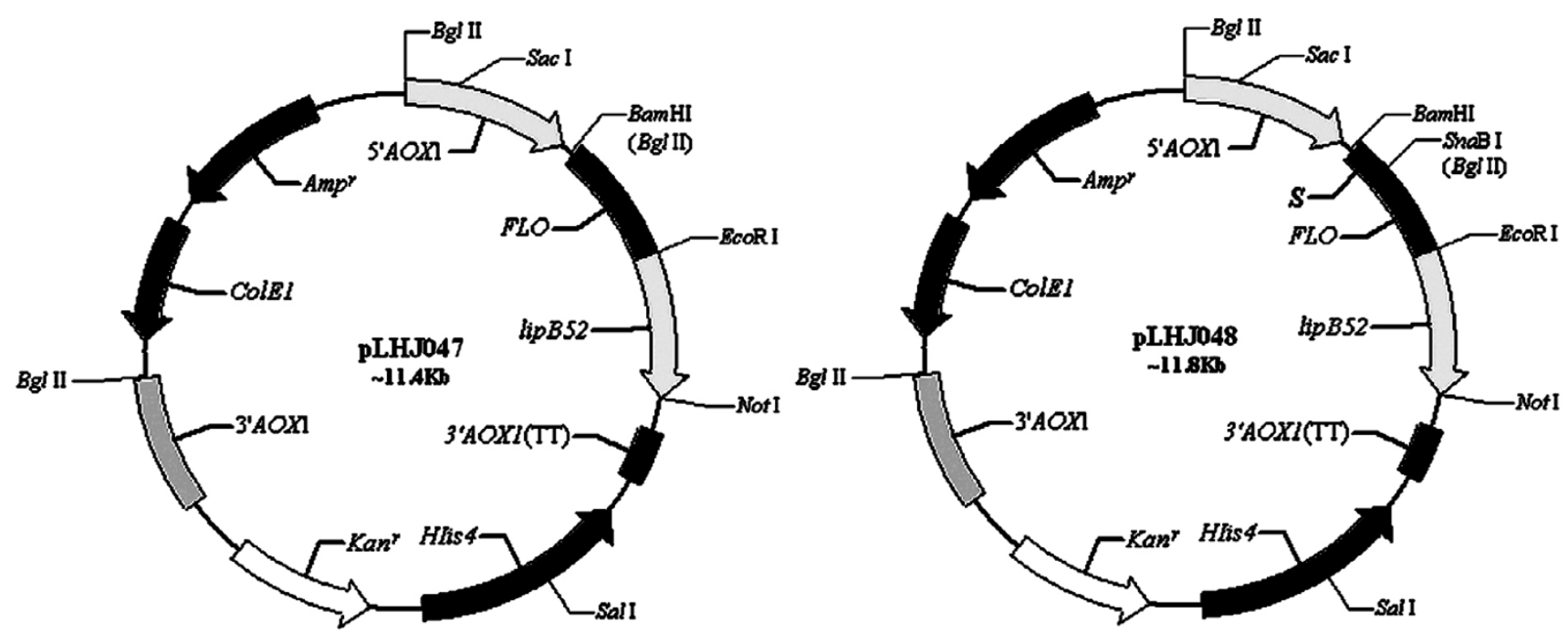

Figure I

The structure of the expression plasmid pLHJ047 and p LHJ048. 5'AOXI, alcohol oxidase I promoter; S, $\alpha$-factor signal sequence for secretion in Pichia; FLO, FLO gene coding for FLO protein from Saccharomyces cerevisiae; lipB52, lipase gene lipB52 cloned in frame and downstream of the FLO sequence; 3'AOXI(TT), transcriptional terminator from pichia pastoris AOX I gene; HIS4, pichia wild-type gene coding for histidinol dehydrogenase and used to complement Pichia his4- strains; kan', Kanamycin resistance gene from Tn903 which confers resistance to G4I8 in Pichia; 3'AOXI, Sequences from the AOXI gene that are further $3^{\prime}$ to the TT sequences; CoEI, E. coli origin of replication; Ampr. Ampicillin resistance gene. 
secretion signal sequence in pLHJ047 was the one from FLO.

The recombinant plasmids linearized with Sal I were electroporated into Pichia pastoris KM71 as described in Methods. The lipase gene was expressed under the control of the $A O X 1$ promoter and the displayed lipase activity were detected by BMMY medium plates supplemented with $1 \%$ olive oil and $0.002 \%$ rhodamine $B$, the expression pattern can be determined by the fluorescent halo around them. The single transformant colony with lipase activity was inoculated and named as KM71-pLHJ047 and KM71pLHJ048, respectively. By using the total DNA of KM71pLHJ047 and KM71-pLHJ048 as the template, a DNA fragment with the same size as lipase gene lipB52 was obtained with primers LipB52Pf-EcoR I and LipB52Pr-Not I by PCR amplification (total DNA of Pichia pastoris KM71 transfected with the plasmid pPIC9K was used as the negative control template), which convinced that the KM71pLHJ047 and KM71-pLHJ048 were recombinant Pichia pastoris with lipase gene lipB52. The lipase activity reached their maximum (92 and $89 \mathrm{U} / \mathrm{g}$ dry cell, $p$-nitrophenolcaprate used as substrate, assayed at $37^{\circ} \mathrm{C}, \mathrm{pH} 8.0$ ) after induced for $96 \mathrm{~h}$, while the lipase LipB52 displayed on Saccharomyces cerevisiae EBY100-pLHJ026 reached its maximum ( $92 \mathrm{U} / \mathrm{g}$ dry cell, assayed under the same condition) after induced for $48 \mathrm{~h}$ (Fig. 2) and the cells were harvested for further analysis.

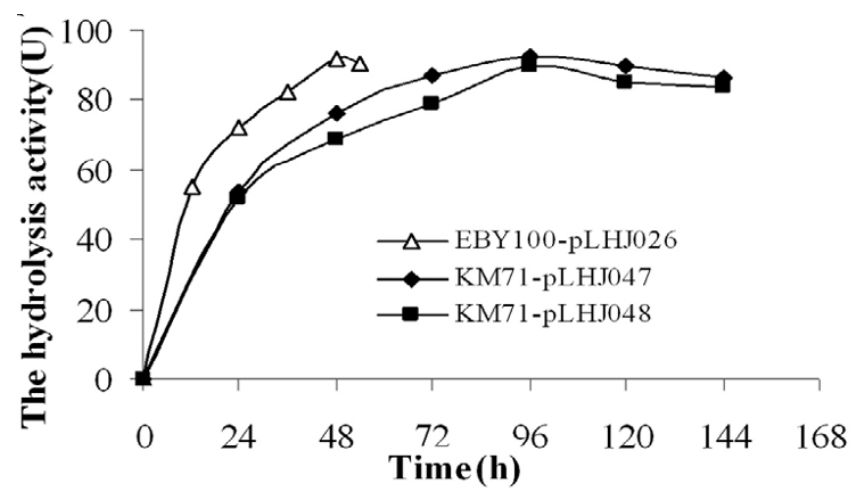

Figure 2

The curve of displayed lipase production. The lipase activity produced by pichia pastoris KM7I-pLHJ047 reached its maximum $92 \mathrm{U} / \mathrm{g}$ dry cell after induced for $96 \mathrm{~h}$; The lipase activity produced by pichia pastoris KM7I-pLHJ048 reached its maximum $89 \mathrm{U} / \mathrm{g}$ dry cell after induced for $96 \mathrm{~h}$; The lipase activity produced by Saccharomyces cerevisiae EBY I00-pLHJ026 reached its maximum $92 \mathrm{U} / g$ dry cell after induced for $48 \mathrm{~h}$. Assayed under the same condition: $p$-nitrophenol-caprate used as substrate, assayed at $37^{\circ} \mathrm{C}, \mathrm{pH} 8.0$.

\section{Localization of the displayed lipase LipB52}

Immunofluorescent labeling of cells was performed as described in Methods. The rabbit polyclonal anti-LipB52 antiserum was used as the primary antibody and the FITCconjugated goat anti-rabbit immunoglobulin $\mathrm{G}$ was used as the secondary antibody. The green fluorescence outlining the immunostained LipB52 cells were clearly observed by the confocal laser scanning microscopy (CLSM) on the recombinant KM71-pLHJ047 and KM71-pLHJ048, the Pichia pastoris KM71 cells harboring the control plasmid pPIC9k were not immunostained (Fig. 3). The results con-

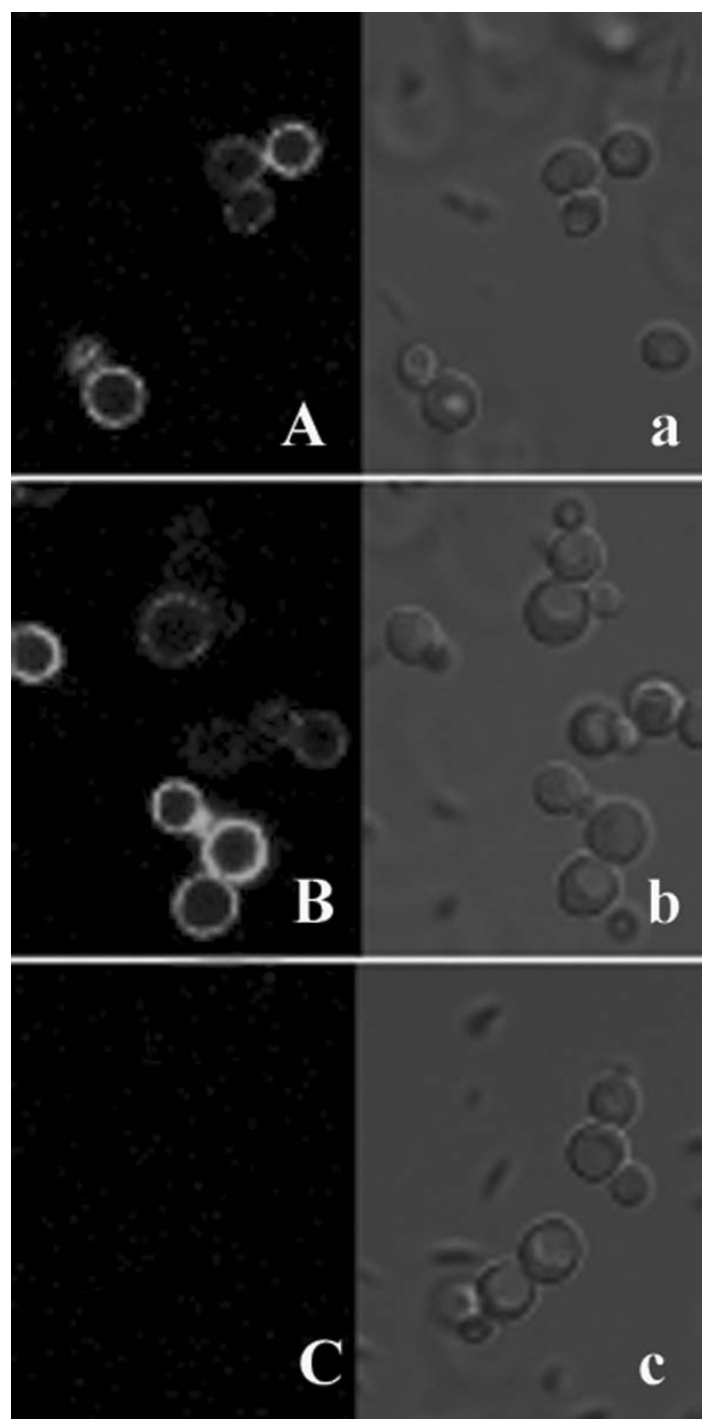

\section{Figure 3}

Detection of the recombinant Pichia pastoris with immunofluorescence. Fluorescence micrographs (panels $A, B$, and $C$ ) and differential interference contrast micrographs (panels a, b, and c) are shown. Panels $A$ and a, Pichia pastoris KM7I-pLHJ047; panels B and b, Pichia pastoris KM7Ip LHJ048; panels C and c, Pichia pastoris KM7I-pPIC9K (control). 
firmed that the LipB52 were displayed on the Pichia pastoris KM71 cell surface.

Characterization and comparison of the displayed lipases The $p$-nitrophenol ester with carbon chain length ranging from $\mathrm{C}_{10}$ to $\mathrm{C}_{18}\left(\mathrm{C}_{10}, \mathrm{C}_{12}, \mathrm{C}_{14}, \mathrm{C}_{16}, \mathrm{C}_{18}\right)$ was used as the substrate to characterize the displayed lipase LipB52 produced by KM71-pLHJ047 and KM71-pLHJ048. The lipase LipB52 displayed on Pichia pastoris KM71 cell surface exhibited evident hydrolysis activity towards the p-nitrophenol ester, but the optimum substrate was $p$-nitrophenol-caprate $\left(\mathrm{C}_{10}\right)$. Lipase LipB52 displayed on Pichia pastoris and Saccharomyces cerevisiae exhibited similar substrate specificity (Fig. 4). The lipase LipB52 displayed on Pichia pastoris KM71-pLHJ047 and KM71-pLHJ048 cell surface have a temperature optimum of $40^{\circ} \mathrm{C}$ at $\mathrm{pH} 8.0$. The hydrolysis activity reached 94 and $91 \mathrm{U} / \mathrm{g}$ dry cell respectively (assayed under their optimum condition). The lipase LipB52 displayed on Saccharomyces cerevisiae EBY100-pLHJ026 cell surface had a temperature optimum of $37^{\circ} \mathrm{C}$ at pH8.0, its maximum activity was $92 \mathrm{U} / \mathrm{g}$ dry cell. The lipase LipB52 displayed on Pichia pastoris KM71pLHJ047 and KM71-pLHJ048 cell surface retained over $90 \%$ activity after incubation at $60^{\circ} \mathrm{C}$ for 2 hours at $\mathrm{pH}$ 7.0 , and they can still retained about $80 \%$ activity after incubation for 3 hours. They exhibited better stability than the lipase LipB52 displayed on Saccharomyces cerevisiae EBY100-pLHJ026 cell surface (Fig. 5). The transesterification activity of the displayed lipases had no evident difference (Fig. 6).

\section{Discussion}

Many reports indicated that the active site of Pseudomonas lipase was located at the C-terminal region [17-20], the

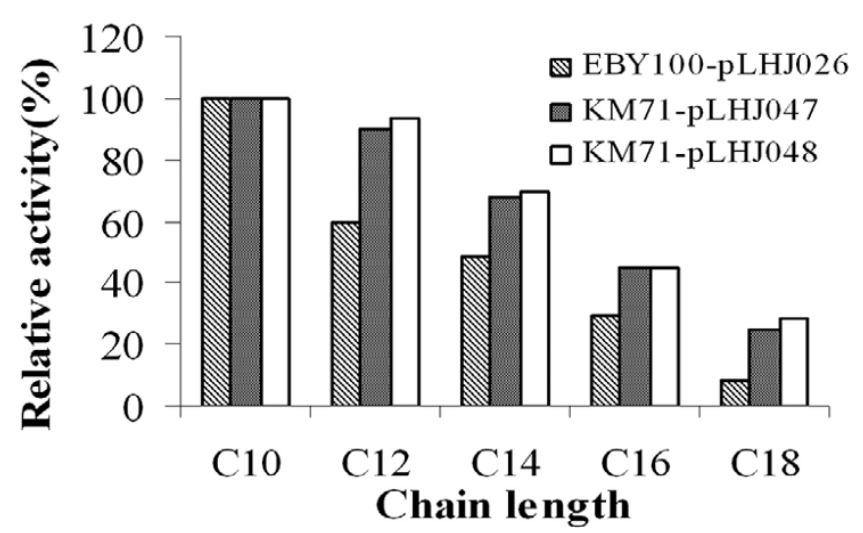

Figure 4

The substrate specificity of the displayed lipases. Lipase LipB52 displayed on Pichia pastoris and Saccharomyces cerevisiae exhibited evident hydrolysis activity towards the $p$ nitrophenol ester, but the optimum substrate was $p$-nitrophenol-caprate $\left(\mathrm{C}_{10}\right)$.

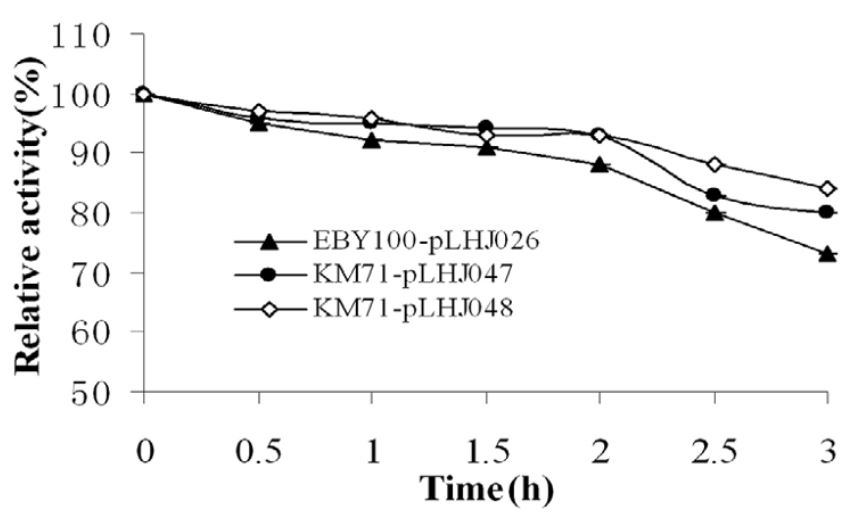

Figure 5

The effect of temperature on stability of the displayed lipases. The lipase LipB52 displayed on Pichia pastoris KM7I-pLHJ047 and KM7I-pLHJ048 cell surface retained over $90 \%$ activity after incubation at $60^{\circ} \mathrm{C}$ for 2 hours at $\mathrm{pH}$ 7.0 , and they can still retained about $80 \%$ activity after incubation for 3 hours. The lipase LipB52 displayed on Saccharomyces cerevisiae EBY 100-pLHJ026 retained near $90 \%$ activity after incubation at $60^{\circ} \mathrm{C}$ for 2 hours at $\mathrm{pH} 7.0$ and it can only retained about $70 \%$ activity after incubation for 3 hours.

lipase displayed on Saccharomyces cerevisiae cell surface by its C-terminus was fused to the cell-wall-anchored protein, $\alpha$-agglutinin, exhibited no activity towards olive oil and a very low enzymatic activity towards $p$-nitrophenol butyrate [21]. The FLO protein is thought to produce cell adhesion via noncovalent interaction of its flocculation functional domain with the mannan chain of the cell wall. Its C-terminus was used to fuse with the N-terminus of target protein, it was successfully used to display active

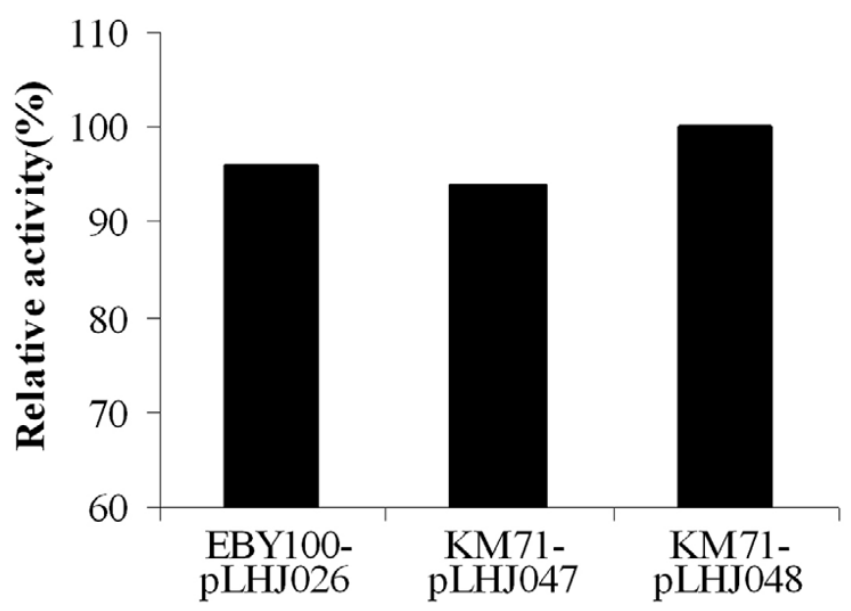

Figure 6

Comparison on transesterification activity of the displayed lipases. The displayed lipases exhibited similar transesterification activity. 
lipase based on Saccharomyces cerevisiae [8]. Considering the similarity between the cell walls of Saccharomyces cerevisiae and Pichia pastoris and the adhesive ability of the FLO protein, we attempted to utilize the relevant domain in a surface display system based on Pichia pastoris.

We successfully developed a Pichia pastoris surface display system utilizing flocculation functional domain of FLO protein, and had the lipase LipB52 expressed and displayed on Pichia pastoris KM71 cell surface. In the present study, two recombinant plasmids (pLHJ047 and pLHJ048) with the same components except the secretion signal sequences were constructed. The secretion signal sequence in pLHJ048 is the $\alpha$-factor secretion signal sequence, while the secretion signal sequence in pLHJ047 is the one from FLO. As shown in the results, the signal sequence of $F L O$ exhibits similar effect to $\alpha$-factor signal sequence in Pichia pastoris. This Pichia pastoris surface display system is also expected to be effective for N-terminal immobilization of target proteins whose catalytic site is near its C-terminus.

The lipase LipB52 displayed on Pichia pastoris KM71 cell surface exhibited some similar biochemical characteristics to that displayed on Saccharomyces cerevisiae EBY100pLHJ026 cell surface, but better stability. As shown in Tab. 1 , the lipase gene was integrated into the genome when displayed on Pichia pastoris cell surface, it could be expressed steadily and can be fermented by using complete medium. However, the lipase gene was cloned in the episomal plasmid when displayed on Saccharomyces cerevisiae cell surface, it must be fermented by using minimal medium. Although the Pichia pastoris induction time was longer than Saccharomyces cerevisiae, the Pichia pastoris dry cell weight per liter (DCW/L) ferment culture was about 5 times than Saccharomyces cerevisiae. Further more the galactose used as the inducer for expressing lipase in Saccharomyces cerevisiae was more costly than the methanol used in Pichia pastoris. All these implied that the lipase displayed on Pichia pastoris cell surface is more suitable for being used as whole-cell biocatalysts than that displayed on Saccharomyces cerevisiae cell surface.

\section{Conclusion}

A Pichia pastoris surface display system utilizing flocculation functional domain of FLO protein was developed, and the activity lipase LipB52 was expressed and displayed on Pichia pastoris KM71 cell surface. The lipase displayed on Pichia pastoris cell surface was more suitable for being used as whole-cell biocatalysts than that displayed on Saccharomyces cerevisiae cell surface.

\section{Methods}

Strains, vectors, culture media and enzymes

Escherichia coli DH5 $\alpha$, used as the recipient strain for recombinant plasmids, was grown in LB medium $(1 \%$ tryptone, $0.5 \%$ yeast extract, $1 \% \mathrm{NaCl}, \mathrm{pH} 7.0$ ) at $37^{\circ} \mathrm{C}$. The FLO gene was cloned from Saccharomyces cerevisiae ATCC 60715 (MATa FLO8 his4 leu2 STA1). The recombinant Saccharomyces cerevisiae EBY100-pLHJ026 was constructed previously, the active lipase LipB52 was displayed on its cell surface. Yeast was grown in complete medium (YPD: $1 \%$ yeast extract, $2 \%$ peptone, $2 \%$ glucose) or selective medium (MD: $1.34 \%$ yeast nitrogen base, $4 \times 10^{-5} \%$ biotin, $2 \%$ dextrose, $2 \%$ agar). BMGY (1\% yeast extract, $2 \%$ peptone, $100 \mathrm{mM}$ potassium phosphate, $\mathrm{pH}$ 6.0, $1.34 \%$ YNB, $4 \times 10^{-5} \%$ biotin, $1 \%$ glycerol) and BMMY ( $1 \%$ yeast extract, $2 \%$ peptone, $100 \mathrm{mM}$ potassium phosphate, $\mathrm{pH} 6.0,1.34 \% \mathrm{YNB}, 4 \times 10^{-5} \%$ biotin, $0.5 \%$ methanol) were used for the recombinant Pichia pastoris. The Pichia pastoris KM71 and pPIC9K were purchased from Invitrogen Corporation. Saccharomyces cerevisiae EBY100pLHJ026 (recombinant Saccharomyces cerevisiae displayed lipase LipB52, stored in our laboratory) were grown in YNB-CAA medium $(0.67 \%$ yeast nitrogen base, $0.5 \%$ casamino acids) containing $2 \%$ glucose or galactose. The exTaq DNA polymerase, restriction enzymes, T4 DNA ligase and modification enzymes were purchased from TaKaRa Biotechnology (Dalian, China) Co., Ltd.

\section{Nucleic acid manipulation}

DNA was purified and manipulated essentially as described by Sambrook et al [22]. DNA was sequenced with the dideoxy chain-termination method by an ABI 3730 automated sequencer from both strands by Invitrogen Biotechnology (Shanghai, China).

\section{Construction of the FLO-lipB52 surface expression vectors for Pichia pastoris}

To amplify the FLO gene from Saccharomyces cerevisiae ATCC 60715 chromosomal DNA, the following two oligonucleotides were used as primers: FLOf-Bgl II (5'-

Table I: Comparison of the properties of the recombinant $S$. cerevisiae and $P$. pastoris.

\begin{tabular}{lcccc}
\hline & Culture medium for expression & Promoter/lnducer & Location of the target gene & DCW/La/lnduction time \\
\hline EBYI00-pLHJ026 & YNB-CAA containing glucose or galactose & GALI/galactose & Cloned in the episomal plasmid & $5.6 \mathrm{~g} / 2$ days \\
KM7I-pLHJ047 & BMGY, BMMY & AOXI/methanol & Integrated into genome & $26.3 \mathrm{~g} / 4 \mathrm{days}$ \\
KM7I-pLHJ048 & BMGY, BMMY & AOXI/methanol & Integrated into genome & $25.6 \mathrm{~g} / 4$ days \\
\hline
\end{tabular}

${ }^{a}$ DCW/L, Dry Cell Weight per liter ferment culture. 
acatagatcttatgacaatgcctcatcgctatatgttttt-3') and FLOr-EcoRI (5'-gatgaattcggtgatttgtcctgaagatgatgatgacaaa-3'). Primers LipB52Pf-EcoR I (5'-aaagaattcccaacaaaaagagaggcaacagcaatg-3) and LipB52Pr-Not I (5'-aaagcggccgctccctccccaccttgtcgtcagg-3') were synthesized based on the sequence of lipB52 (GenBank accession number AY623009) and used to amplify lipB52 gene from the plasmid pLHJ018 containing lipB52 [7]. The PCR was performed as following: $95^{\circ} \mathrm{C} 10 \mathrm{~min}$, followed by 30 cycles of amplification $\left(95^{\circ} \mathrm{C} 1 \mathrm{~min}, 58^{\circ} \mathrm{C} 45 \mathrm{sec}\right.$ and $\left.72^{\circ} \mathrm{C} 1 \mathrm{~min}\right)$ and $72^{\circ} \mathrm{C} 10$ min after that. The purified PCR products, FLO and lipB52 gene, were digested with EcoR I, respectively, and ligated with T4 DNA ligase. Then the ligation product was used as the template to amplify the FLO-lipB52 fusion gene with primers FLOf-Bgl II and LipB52Pr-Not I. The FLO-lipB52 PCR product was purified and divided into two parts. One was digested with $B g l$ II and blunted with T4 DNA polymerase, then digested with Not I and ligated with pPIC9K digested with SnaB I and Not I, which reserved the $\alpha$-factor secretion signal sequence. The other part was digested with $B g l$ II and Not I, and ligated with pPIC9K digested with BamH I ( $B g l$ II and BamH I have the same cohesive end) and Not I, which discarded the $\alpha$-factor secretion signal sequence. The recombinants were screened and identified with restriction enzymes and sequencing.

\section{Pichia pastoris transformation and expression}

Electrocompetent cells of Pichia pastoris KM71 were prepared according to the supplier's instruction [23]. $10 \mu \mathrm{g}$ recombinant plasmid linearized with $S a l$ I was mixed with $80 \mu$ lelectrocompetent cells, and electroporated by means of pulse discharge $(1,500 \mathrm{~V}, 25 \mu \mathrm{F}$, Bio-Rad Gene Pulser) for $5 \mathrm{~ms}$. After pulsing, $1 \mathrm{ml}$ ice-cold $1 \mathrm{M}$ sorbitol was immediately added to the cuvette. Then, $200 \mu$ l aliquots were spread on MD plates, and the plates were incubated at $30^{\circ} \mathrm{C}$ to screen for $\mathrm{His}^{+}$transformants according to their capacity to grow in the absence of histidine.

To detect the displayed lipase activity, the following manipulation was performed. $\mathrm{His}^{+}$clones were grown on BMGY plates at $30^{\circ} \mathrm{C}$ over night, and then transferred onto BMMY plates supplemented with $1 \%$ olive oil and $0.002 \%$ rhodamine $\mathrm{B}$ and induced at $30^{\circ} \mathrm{C}$. $150 \mu \mathrm{l}$ fresh methanol were added in the lid of plates every $24 \mathrm{~h}$ to induce the lipase protein expression. The recombinant strains with displayed active lipases were screened by BMMY plates supplemented with olive oil as substrate and rhodamine $\mathrm{B}$ as indicator. The recombinant strains were also identified by PCR with primers LipB52Pf-EcoR I and LipB52Pr-Not I.

Scale-up of expression was performed according to the supplier's instruction [23]. The recombinant strains were grown in $100 \mathrm{ml} \mathrm{BMGY}$ medium at $30^{\circ} \mathrm{C}, 250 \mathrm{rpm}$ until the culture reached $\mathrm{OD}_{600}=2.0-6.0$. The cells were harvested by centrifugation and resuspended at a five-fold concentration in $20 \mathrm{ml}$ BMMY medium to induce protein expression. The cells were incubated for 6 days at $30^{\circ} \mathrm{C}$, $250 \mathrm{rpm}$, and fresh methanol was added to a concentration of $0.5 \%$ to maintain induction every $24 \mathrm{~h}$. The cells were harvested by centrifugation for activity assay after washed with PBS (10 mM potassium phosphate buffer, pH 7.2, containing $150 \mathrm{mM}$ sodium chloride). The harvested cells were immediately stored at $-20^{\circ} \mathrm{C}$ over night and then quickly transferred to the lyophilizer (Freezon12, Labconco, USA) for 48 hours.

\section{Detection and characterization of the displayed lipase}

Immunostaining was performed as follows. The rabbit polyclonal anti-LipB52 antiserum was raised against the recombinant LipB52 produced by Pichia pastoris KM71pLHJ018 [7] and used as the primary antibody. The incubated yeast cells were washed with PBS. The cells were incubated with the primary antibody (1:50 diluted with $2 \%$ bovine serum albumin) on ice for $30 \mathrm{~min}$ with occasional mixing. After the cells had been washed with PBS, the secondary antibody, fluorescein isothiocyanate (FITC)-conjugated goat anti-rabbit immunoglobulin G (Jackson ImmunoResearch Laboratories Inc. USA, 1:200 diluted with $2 \%$ bovine serum albumin), was added and allowed to react with the cells on ice for $30 \mathrm{~min}$ in dark. The cells were then washed with PBS and detected by the confocal laser scanning microscopy (Zeiss LSM 510 META).

The release of $p$-nitrophenol ( $p$-NP) from $p$-NP -derivative substrates was measured as described[24,25]. One unit (U) of hydrolysis activity was defined as the amount of enzyme that released $1 \mu \mathrm{mol}$ of $p$-NP per minute under the assay conditions. The transesterification activity was assayed by gas chromatography as described [26].

\section{Expression of lipase LipB52 displayed on Saccharomyces cerevisiae EBYI00-pLHJ026}

Inoculate a single EBY100-pLHJ026 colony into $10 \mathrm{ml}$ YNB-CAA containing $2 \%$ glucose and grow overnight at $30^{\circ} \mathrm{C}$ with shaking. After the $\mathrm{OD}_{600}=2-5$, centrifuge the cell culture at $8,000 \mathrm{rpm}$ for $5 \mathrm{~min}$ at room temperature. Then resuspend the cell pellet in YNB-CAA medium containing $2 \%$ galactose to an $\mathrm{OD}_{600}$ of 0.5 to 1 . Immediately remove a volume of cells equivalent to $2 \mathrm{OD}_{600}$ units (e.g. $\mathrm{OD}_{600}$ of 0.5 , remove $4 \mathrm{ml}$ ) and place on ice. This was used as zero time point. Incubate the cell culture at $20^{\circ} \mathrm{C}$ with shaking. Assay the cell culture every $12 \mathrm{~h}$ to determine the optimal induction time for maximum display. For each time point, read the $\mathrm{OD}_{600}$ and remove a volume of cells that is equivalent to $2 \mathrm{OD}_{600}$ units. After the maximum display, the cells were harvested by centrifugation for activity assay after washed with PBS and lyophilized. 


\section{Authors' contributions}

ZJ carried out construction of vectors, the sequence alignment and drafted the manuscript. RR carried out Pichia pastoris transformation and expression, participated in the immunofluorescent labeling. BG carried out detection and characterization of the displayed lipase. XT participated in the immunofluorescent labeling. YM performed the statistical analysis. DW participated in the design of the study and coordination and helped to draft the manuscript. All authors read and approved the final manuscript.

\section{Acknowledgements}

This work was supported by the following grant: the Ministry of Science and Technology, Basic Research project, No. 2002CCA400; High Technology Research and Development Program of China (863 Program), No. 2006AA020203; Program for New Century Excellent Talents in University, No. NCET-04-04I I; Science and Technology Commission of Shanghai Municipality, No. 06XDI 4006.

\section{References}

I. Dharmsthiti S, Kuhasuntisuk B: Lipase from Pseudomonas aeruginosa LP602: biochemical properties and application for wastewater treatment. J Ind Microbiol Biotech 1999, 21:75-80.

2. Jaeger KE, Dijstra BW, Reetz MT: Bacterial biocatalyst: Molecular biology, three-dimensional structures, and biotechnological applications of lipases. Annu Rev Microbiol I999, 56:3 I5-35I.

3. Matsumoto T, Ito M, Fukuda $\mathrm{H}$, Kondo A: Enantioselective transesterification using lipase-displaying yeast whole-cell biocatalyst. Appl Microbiol Biotechnol 2004, 64:48I-485.

4. Amada K, Haruki M, Imanaka T, Morikawa M, Kanaya S: Overproduction in Escherichia coli, purification and characterization of a family I.3 lipase from Pseudomonas sp. MIS38. Biochim Biophys Acta 2000, I478:20I-2I 0.

5. Beven CA, Dieckelmann M, Beacham IR: A strain of Pseudomonas fluorescens with two lipase-encoding genes, one of which possibly encodes cytoplasmic lipolytic activity. J Appl Microbiol 200I, 90:979-987.

6. Kojima Y, Kobayashi M, Shimizu S: A Novel lipase from Pseudomonas fluorescens HU380: gene cloning, overproduction, renaturation-activation, two-step purification, and characterization. J Biosci Bioeng 2003, 96:242-249.

7. Jiang $Z$, Zheng $Y$, Luo $Y$, Wang G, Wang H, Ma $Y$, Wei D: Cloning and expression of a novel lipase gene from Pseudomonas fluorescens B52. Mol Biotechnol 2005, 31:095-102.

8. Matsumoto T, Fukuda $\mathrm{H}$, Ueda M, Tanaka A, Kondo A: Construction of yeast strains with high cell surface lipase activity by using novel display systems based on the FLO flocculation functional domain. Appl Environ Microbiol 2002, 68:45I7-4522.

9. Washida M, Takahashi S, Ueda M, Tanaka A: Spacer-mediated display of active lipase on the yeast cell surface. Appl Microbiol Biotechnol 200I, 56:68I-686.

10. Tanino Takanori, Fukuda Hideki, Kondo Ahihiko: Construction of a Pichia pastoris Cell-Surface Display System Using Flolp Anchor System. Biotechnol Prog 2006, 22:989-993.

II. Ren Ren, Jiang Zhengbing, Liu Meiyun, Tao Xingyi, Ma Yushu, Wei Dongzhi: Display of adenoregulin with a novel Pichia pastoris cell surface display system. Molecular Biotechnology 2007, 35: $103-108$.

12. Cereghino Joan Lin, Cregg James M: Heterologous protein expression in the methylotrophic yeast Pichia pastoris. FEMS Microbiology Reviews 2000, 24:45-66.

13. Bony M, Thines-Sempoux D, Barre P, Blondin B: Localization and cell surface anchoring of the Saccharomyces cerevisiae flocculation protein FLO. J Bacteriol 1997, 179:4929-4936.

14. Miki BL, Poon NH, James AP, Seligy VL: Possible mechanism for flocculation interactions governed by gene $F L O I$ in Saccharomyces cerevisiae. J Bacteriol 1982, I 50:878-889.
15. Teunissen A, Holub E, Van Der Hucht J, Van Den Bergh JA, Steensma $H Y$ : Sequence of the open reading frame of the FLOI gene from Saccharomyces cerevisiae. Yeast 1993, 9:423-427.

16. Watari J, Takata Y, Ogawa M, Sahara H, Koshino S, Onnela ML, Airaksinen U, Jaatinen R, Penttila M, Keranen S: Molecular cloning and analysis of the yeast flocculation gene FLOI. Yeast 1994, 10:21I-225

17. Lee J, Boyapati G, Song K, Rhee S, Kim C: Cloning and sequence analysis of the estA gene encoding enzyme for producing (R)-beta-acetylmercaptoisobutyric acid from Pseudomonas aeruginosa 100I. J Biosci Bioeng 2000, 90:684-687.

18. Lee J, Suh SW, Shin S: Computational studies of essential dynamics of Pseudomonas cepacia lipase. J Biomol Struct Dyn 2000, 18:297-309.

19. Nardini M, Lang DA, Liebeton K, Jaeger KE, Dijkstra BW: Crystal structure of pseudomonas aeruginosa lipase in the open conformation. The prototype for family I.I of bacterial lipases. Biol Chem 2000, 275:31219-31225.

20. Omori K, Idei A, Akatsuka H: Serratia ATP-binding cassette protein exporter, Lip, recognizes a protein region upstream of the C terminus for specific secretion. J Biol Chem 200I, 276:27|II-27II 9 .

21. Schreuder MP, Mooren AT, Toschka HY, Verrips CT, Klis FM Immobilizing proteins on the surface of yeast cells. Trends Biotechnol 1996, 14:1 I5-I20.

22. Sambrook J, Fitsch EF, Maniatis T: Molecular Cloning: A Laboratory Manual Cold Spring Harbor, Cold Spring Harbor Press; 1989.

23. Invitrogen: A manual of methods for expression of recombinant proteins in Pichia pastoris. . Catalog no. KI7I0-0I

24. Maurich $V$, Zacchigna M: $p$-Nitrophenyl laurate: a substrate for the high-performance liquid chromatographic determination of lipase activity. J Chromatogr 1991, 566:453-459.

25. Prim N, Blanco A, Martý'nez J, Pastor FIJ, Diaz P: est A, a gene coding for a cell-bound esterase from Paenibacillus sp. BP-23, is a new member of the bacterial subclass of type $B$ carboxylesterases. Res Microbiol 2000, 15 I:303-312.

26. Luo Y, Zheng Y, Jiang Z, Ma Y, Wei D: A novel psychrophilic lipase from Pseudomonas fluorescens with unique property in chiral resolution and biodiesel production via transesterification. Appl Microbiol Biotechnol 2006, 73(2):349-355.
Publish with Biomed Central and every scientist can read your work free of charge

"BioMed Central will be the most significant development for disseminating the results of biomedical research in our lifetime. "

Sir Paul Nurse, Cancer Research UK

Your research papers will be:

- available free of charge to the entire biomedical community

- peer reviewed and published immediately upon acceptance

- cited in PubMed and archived on PubMed Central

- yours - you keep the copyright
BiolMedcentral 